\title{
CONTRATAÇÃO NA EAD: CLT OU MEI? DESAFIOS E POSSIBLIDADDES
}

\author{
RIO DE JANEIRO/RJ AGOSTO/2018
}

\author{
Mônica Campos Santos Mendes - UNIGRANRIO - monica.campos@outlook.com.br \\ Marjorie de Almeida Araújo - FGF- Faculdade da Grande Fortaleza - aacsj@hotmail.com
}

Tipo: Investigação Científica (IC)

Natureza: Planejamento de Pesquisa

Categoria: Estratégias e Políticas

Setor Educacional: EDUCAÇÃO SUPERIOR

\begin{abstract}
RESUMO
O artigo tem como propósito analisar um movimento que ocorre no universo da educação a distância com a contratação de profissionais, inclusive docentes, no regime de MEI - Microempreendedor Individual, por parte das fornecedoras de produtos para EaD e, inclusive algumas Instituições de Ensino. Para isso, utilizou-se como base os pressupostos da metodologia qualitativa pautada na pesquisa bibliográfica e na experiência das autoras. Como resultado parcial, pode-se observar que, embora o exercício da docência pressuponha vínculo com a Instituição de Ensino, há demandas de trabalhos neste formato, aliadas ao home office. Afinal, qual é a relação de um docente com a IE e seus alunos? Como construir o saber sem este vínculo? Conclui-se, portanto, que são necessários debates e divulgação acerca do tema, para que esta relação não se perca no universo mercadológico em detrimento da qualidade do ensino e da aprendizagem.
\end{abstract}

Palavras-chave: Educação a distância, Trabalho docente, ensino e aprendizagem, CLT, MEI 


\section{INTRODUÇÃO}

Nos últimos anos o mundo do trabalho tem se modificado por conta dos recursos tecnológicos, profissões desaparecem e outras surgem. No universo da educação a distância não tem sido diferente. Para compor uma equipe multidisciplinar faz-se necessário encontrar profissionais com qualificações e competências diversas. Também muda o espaço de atuação, formam-se equipes virtuais que, recebem uma demanda de entrega com prazos e papéis bem definidos. Neste cenário, vê-se incluir o docente, na posição de tutor, de conteudista, de roteirista de vídeos aulas, na elaboração de atividades avaliativas ou não, etc. Surgindo outro aspecto desta relação, a atuação home office ou teletrabalho, como a reforma trabalhista assim o definiu na Lei 13.467/2017 (BRASIL, 2017). Nesse sentido, Whale (2017), caracteriza essa espécie de trabalho como:

Trabalho predominantemente fora das dependências do empregador. Contrato escrito. Responsabilidade pelo fornecimento e manutenção de equipamentos de $\mathrm{TI}$ e pelo reembolso de despesas feitas pelo empregado a ser definida no contrato escrito. Possível a mudança de sistema presencial para home office e vice-versa por mútuo acordo. Ou, no caso de mudança do sistema de home office para presencial, por imposição do empregador. - Comparecimento às dependências do empregador não descaracteriza o regime de teletrabalho. Empregados em home-office não têm direito a horas extras. (WAHLE, 2017, p. 6).

Além disso, frente à crise econômica que o Brasil vem sofrendo, estratégias têm sido traçadas no intuito de reduzir gastos considerados desnecessários, a fim de garantir a existência de verbas indispensáveis para investimento em tecnologia, algo de extrema necessidade ao bom desenvolvimento da Educação a Distância.

Este artigo é de grande relevância para a comunidade acadêmica, pois demonstra para os profissionais e empresas ligadas ao ramo da Educação a Distância, alguns critérios a serem observados na modalidade empresarial MEI (microempreendedor individual).

\section{A REGULAMENTAÇÃO DO MEI E SUAS IMPLICAÇÕES}

Conforme o Portal do Microempreendedor, este é o pequeno empresário individual que atende as condições pré-estabelecidas: a) tenha faturamento limitado a $R \$ 81.000,00$ por ano; b) Que não participe como sócio, administrador ou titular de outra empresa; c) 
Contrate no máximo um empregado; d) Exerça uma das atividades econômicas previstas no Anexo XIII, da Resolução do Comitê Gestor do Simples Nacional de no 94/2011, o qual relaciona todas as atividades permitidas ao MEI (BRASIL, 2018).

As atividades permitidas para este registro estão previstas no Comitê Gestor do Simples Nacional - CGSN, Anexo XIII da Resolução CGSN n. 94/2011 podendo o profissional ter registro como microempreendedor individual e vínculo celetista com anotação da CTPS (certeira de trabalho e previdência social), desde que, esta seja a atividade principal e a outra (MEI) seja desempenhada nas horas vagas (BRASIL, 2018).

No âmbito da educação as atividades autorizadas para registro são bastante restritas. Especialmente para o contexto da EaD. Para um docente cabe-Ihe apenas: Instrutor de cursos gerenciais independente; professor particular independente; instrutor de cursos preparatórios independente; professor de idiomas independente e professor de informática independente.

Algumas empresas que atuam produzindo produtos para a educação a distância e até mesmo Instituições de Ensino têm solicitado que os contratados tenham CNPJ (cadastro nacional de pessoa jurídica), podendo ser adquirido na forma de microempreendedor. Essa forma de contratação tem se dado para a produção de materiais didáticos, objetos avaliativos, revisão, Tutoria temporária, dentre outras possibilidades.

\section{INSTITUIÇÕES FORNECEDORAS DE PRODUTOS E A REALIDADE MEI}

Percebe-se uma movimentação das fornecedoras de produtos para EaD e de IE na busca por contratar profissionais com registro de MEI. E a demanda por este modelo de contratação tem sido correspondida por parte de alguns profissionais de educação, embora gere desconforto em outros pois a preferência é o contrato celetista por representar, ainda que relativamente, uma segurança ao trabalhador.

De acordo o Censo ABED 2016, verifica-se que a produção de conteúdo e diversos outros materiais se destacam, o que representa uma significativa oportunidade para contratos no formato analisado por este trabalho:

As instituições fornecedoras e formadoras destacam-se exatamente na prestação de serviços ligados ao conteúdo e à capacitação - 92\% fornecem cursos de EAD completos, $83 \%$ fornecem materiais educacionais e personalizam conteúdos de outros 
fornecedores e 78\% realizam capacitação (CENSO ABED 2016, p. 160).

Outro fator relevante é a remuneração, percebe que esta vem caindo gradativamente, o que também se comprova no Censo ABED 2016. O contrato de MEI parece não mudar este cenário, pois as autoras têm sido contratadas e os valores pelo serviço prestado tem seguindo esta tendência:

No caso dos tutores, $32 \%$ das instituições pagam menos de $R \$ 30$ por hora, e essa proporção vai decrescendo até a faixa de $1 \%$, que paga entre $R \$ 66$ e $R \$ 75$ por hora. $O$ interessante é que há $4 \%$ de instituições que pagam mais de $\mathrm{R} \$ 75$ por hora a seus tutores. Os valores pagos aos produtores de conteúdo também decrescem de forma regular, de $16 \%$ de instituições que pagam menos de $R \$ 30$ por hora até $2 \%$ que pagam entre $R \$ 66$ e $R \$ 75$, sendo que $11 \%$ das instituições pagam mais de $R \$ 75$ a esses profissionais (CENSO ABED 2016, p. 135).

Tem-se debatido sobre a regulamentação da profissão de tutor, que carece de uma resolução urgente. Todos os anos, no CIEAD, este tema é abordado e, ainda percebemos situações como a apontada pelo Censo ABED 2016:

Os valores pagos a docentes e tutores variam bastante - de menos de $R \$ 30$ a mais de $\mathrm{R} \$ 75$ por hora. A maioria dos tutores (em 32\% das instituições) recebe menos de $\mathrm{R} \$$ 30 , enquanto em $4 \%$ das instituições eles podem receber mais de $R \$ 75$. Observamos uma influência da categoria administrativa e da região em que trabalham nas faixas de pagamentos. (CENSO ABED 2016, p. 41).

Um ponto despertou a atenção das autoras, no Censo acima referenciado não foi encontrada nenhuma informação quando aos profissionais conteudistas, como, forma de contratação, remuneração etc. Entende-se que, este é um tema que merece atenção do referido Censo para suas futuras edições.

\section{POSSIBLIDIDADE DE CONTRATAÇÃO DE UM MICROEMPREENDEDOR}

A grande vantagem que se percebe para as empresas, sejam Instituições de Ensino ou não, na contratação de quem possui MEI é uma visão mais clara e objetiva de afastamento do vínculo trabalhista, algo que onera muito a folha de pagamento destas.

Entretanto, algumas empresas têm aplicado de forma equivocada a contratação de 
microempreendedores, devendo atentar neste momento, para o aconselhamento de uma boa equipe jurídica, que esteja devidamente atualizada em questões trabalhistas. pessoalidade (o empregado deve ser uma pessoa física); onerosidade (deve desenvolver a atividade mediante a percepção de salário); subordinação (dependência do empregado em relação ao empregador, quanto as ordens, pagamentos, entre outras obrigações trabalhistas); habitualidade (os serviços são prestados habitualmente e não de forma eventual), se estará diante de um contrato de trabalho, onde deverá ser realizada a anotação da CTPS do empregado, com o devido pagamento de todos os direitos trabalhista garantidos pela consolidação das leis do trabalho - CLT (CASSAR, 2008, p. 262/277).

Portanto, a contratação de alguém que possua cadastro de MEI para desenvolver atividades de forma presencial e habitual nas dependências da empresa, não afasta 0 vínculo de emprego, simplesmente, pela existência de um CNPJ. Da mesma forma acontece nas atividades habituais, desenvolvidas pelo mesmo contratado na plataforma de ensino, onde a empresa contabiliza e controla o tempo de acesso, bem como as atividades diárias do prestador de serviço, situação em que poderá ser considerado o vínculo trabalhista.

Sendo feita de forma correta, é uma ótima e pratica forma de evitar cair nas mãos de aventureiros processuais, os quais tentam criar vínculos empregatícios inexistentes com certas empresas.

\section{MICROEMPREENDEDOR: VANTAGENS E DESVANTAGENS}

O MEI regularmente constituído, que realizar os pagamentos das contribuições mensais, passa a usufruir de garantias previdenciárias como auxilio doença, salário maternidade, aposentadoria, pensão e auxilio reclusão, sob encargos bem menores com relação aos valores recolhidos ao INSS pela opção de trabalhador autônomo. Nesse contexto, é necessário dizer que, ao realizar uma atividade como autônomo, o professor receberá por RPA - Recibo de Pagamento Autônomo e terá $11 \%$ do valor retido a título de contribuição previdenciária, mas se estiver na qualidade de microempreendedor, não terá qualquer valor retido, visto que já contribui mensalmente, devendo apenas emitir nota fiscal.

Como MEl é possível registrar um funcionário, contratar máquinas de cartões de crédito, e algumas outras vantagens comerciais propiciadas apenas a quem tem CNPJ. No 
mercado financeiro também são oferecidas taxas reduzidas em empréstimos.

Vale ressaltar, que o registro pode ser cancelado a qualquer momento, sendo essencial que preste sua declaração de seus rendimentos anualmente. Contudo, atenção! Antes de realizar um cadastro como $\mathrm{MEI}$, o profissional da educação deve verificar se realmente se encaixa nessa modalidade, pois se assim não for, poderá ter problemas com a receita federal e um gasto maior quando precisar se enquadrar em outra modalidade empresarial.

No que diz respeito às desvantagens, podemos mencionar o fato de mesmo sem receber qualquer valor como remuneração por um serviço prestado, o professor terá que pagar a contribuição mensal. Por isso, precisa analisar se as atividades desempenhadas e a quantidade de vezes que a executa, são verdadeiramente vantajosos para que se efetue o cadastro.

Em relação aos benefícios previdenciários, a desvantagem está em não garantir a aposentadoria por tempo de contribuição, contabilizando, as contribuições mensais, apenas para efeitos de aposentadoria por invalidez e aposentadoria por idade. Portanto, para efeito de aposentadoria, deverá fazer o recolhimento mensal, independentemente do MEI.

\section{UM BREVE ESCLARECIMENTO À LUZ DA EXPERIÊNCIA COMO MEI}

Fazer o registro como microempreendedor demanda tempo para leitura das regras e procedimentos necessários. Para iniciar o registro deve-se acessar o portal oficial (http://www.portaldoempreendedor.gov.br/), o próximo passo é a emissão de Alvará que, na cidade do Rio de Janeiro deve ser feito pelo portal Carioca Rio (https://carioca.rio/). Precede à solicitação do Alvará, uma Consulta Prévia de Local, que consistem em informar qual o endereço que será utilizado como sede da sua atividade. Só após a emissão do referido Alvará, poderá ser feita a senha para emissão de nota fiscal eletrônica. Senha esta, que será liberada ao comparecer à Prefeitura da cidade, levando os documentos solicitados.

É importante ressaltar que, há uma declaração anual a ser feita sob pena de ter seu registro cancelado. Há impostos de que devem ser pagos mensalmente. Demandando uma organização de características empresárias, uma vez que, há formulários que devem ser preenchidos com as receitas e despesas referentes à atividade do 
microempreendedor.

Ressalte-se que, outra providência necessária é a abertura de conta corrente pessoa jurídica, em Instituição Bancária, cujo serviço é tarifado mensalmente.

Identificou-se que, há complexidade nos procedimentos e, é natural que algumas pessoas tenham mais dificuldades que outras ao fazê-lo.

É importante esclarecer que, os procedimentos para emissão de nota fiscal podem variar conforme a regulamentação de cada Unidade da Federação.

Este relato está sucinto pois não é o propósito orientar a abertura do MEI e sim, pontuar alguns esclarecimentos.

\section{CONSIDERAÇÕES FINAIS}

É inquestionável a seriedade do tema, estamos vivendo uma nova onda onde as relações sociais e de trabalho se transformam e arrastam a educação para um abismo ou, está aí a solução para questões tão debatidas?

Existem vários tipos de empresas fornecedoras, como demonstramos no Censo EAD.BR 2016. Todas têm diversos tipos de soluções, que podem atender a necessidades pontuais ou completas das instituições.

Essas soluções também podem ser genéricas ou personalizadas, dependendo do que a instituição está buscando (CENSO ABED, 2016, p. 29).

O MEI apresenta vantagens para empresas e microempreendedores, porém, há que se ter cuidado para que não fique caracterizada a fraude às leis vigentes no país, sendo perfeitamente aplicável a atividades temporárias ou esporádicas. Assim sendo, contratar um microempreendedor não pode ser considerada uma simples prática de se reduzir ou cortar gastos, pois se assim for, poderá se tornar um grande problema ao invés de uma eficiente solução.

Para as atividades educacionais onde se quer controlar a capacidade técnica dos profissionais, como é o caso da EaD, estando as instituições continuamente investindo na formação continuada do profissional, a melhor forma ainda é garantir a qualidade 
através da contratação de profissionais com vinculo celetista, onde haja investimento no trabalhador, com a contrapartida de um trabalho desenvolvido com comprometimento e alinhado a política da Instituição.

Assim explica Fabio Ulhoa Coelho ao falar sobre a importância da figura do empregado:

São estes que, materialmente falando, produzem ou fazem circular bens ou serviços. $O$ requisito da pessoalidade explica por que não é o empregado considerado empresário. Enquanto este último, na condição de profissional, exerce a atividade empresarial pessoalmente, os empregados, quando produzem ou circulam bens ou serviços, fazemno em nome do empregador. (COELHO, 2013, p.30)

Ademais, nas atividades em que sejam necessárias a pessoalidade, habitualidade, onerosidade e subordinação, é ilegal a contratação de prestador de serviços, a não ser que seja na modalidade de terceirização, o que não é possível se aplicar através do MEI.

Para os profissionais da educação, as vantagens superam as desvantagens quanto ao enquadramento como $\mathrm{MEI}$, desde que se aja dentro da legalidade e cumprindo-se com as regulamentações inerentes a essa forma empresarial. Todavia, caso haja arrependimento, o cadastro pode ser facilmente cancelado, assim como é facilmente realizado.

Portanto, percebe-se ser este um caminho que pode ser útil para ambos, recomenda-se, contudo, que o contrato CLT seja mantido prioritariamente. Pois, visa-se a qualidade da educação e não relações meramente comerciais.

O docente deve ter vínculo com a Instituição de Ensino para o trabalho de mediação e prática de ensino e aprendizagem, sendo lançado mão do MEI para elaboração de conteúdos e outros objetos de aprendizagem.

\section{REFERÊNCIAS}

ABED. Censo EaD: Relatório Analítico da Aprendizagem a Distância no Brasil 2016. São Paulo: Pearson, 2016.

BRASIL. Portal do Empreendedor Individual. Disponível em: 
<http://www.portaldoempreendedor.gov.br> Acesso: 26 mar. 18.

BRASIL. Consolidação das Leis do Trabalho. Disponível em: <http://www.planalto.gov.br/ccivil_03/decreto-lei/Del5452.htm> Acesso em 06 maio. 2018.

BRASIL. Lei da Reforma Trabalhista. Lei no 13.467, de 13 de julho de 2017. Disponível em < http://www.planalto.gov.br/ccivil_03/_ato2015-2018/2017/lei/l13467.htm>. Acesso em 07 mai. 2018.

CASSAR, Volia Bonfim, Direito do Trabalho, 20aㅡ ed. rev. ampl. e atual., Niterói, Editora Impetus, 2008.

COELHO, Fabio Ulhoa. Manual de Direito Comercial: Direito de Empresa. 25. ed. São Paulo: Saraiva, 2013.

WAHLE, José Carlos. ENDEAVOR BRASIL. FERRAMENTA: guia prático da reforma trabalhista: O que muda e como isso afeta o empreendedor? 2017. Disponível em: <http s://images.endeavor.org.br/uploads/2017/11/Ferramenta-Reforma-Trabalhista-v4.pdf>. Acesso em 14 dez. 2017. 